\title{
Methodological Basis of Higher Education Institution Competiveness
}

\section{Assessment}

\author{
Svetlana I. Ashmarina ${ }^{1}$, Gabibulla R. Khasaev ${ }^{1}$ \& Irina A. Plaksina ${ }^{1}$ \\ ${ }^{1}$ Samara State University of Economics, Samara, Russia \\ Correspondence: Svetlana I. Ashmarina, Samara State University of Economics, Sovetskoi Armii Street 141, \\ Samara, 443090, Russia. E-mail: asisamara@mail.ru
}

\author{
Received: December 4, $2014 \quad$ Accepted: December 30, $2014 \quad$ Online Published: January 17, 2015 \\ doi:10.5539/res.v7n2p49 URL: http://dx.doi.org/10.5539/res.v7n2p49
}

\begin{abstract}
The author's standpoint regarding the category definition of "higher education institution competitiveness" is given in the paper. The most important characteristic of the general higher education institution competitiveness is defined as satisfaction of internal stakeholders-employees, achieved by means of implementing two directions: meeting employees' needs in decent working conditions; meeting needs of external stakeholders to the fullest extent allowing personnel to be proud of belonging to a higher education institution. The authors revealed and systematized the factors influencing the level of higher education institution competitiveness. The methodological ideas on higher education institution competitiveness are considered and the authors' technique of a higher education institution competitiveness assessment in educational services markets, scientific research and development, labor and general competitiveness including the following stages is presented: our opinion is that on the whole the technique of a higher education institution competitiveness assessment is to include the following stages: indicators formation of higher education institution competitiveness assessment and their classification according to competitiveness types; indicator distribution of a higher education institution competitiveness assessment in preference manner; an indicator assessment on the basis of the subjective and objective approach; an integrated indicator assessment of higher education institution competitiveness (the general one and by types of competitiveness). The need for use of the subjective and objective approach to a higher education institution competitiveness assessment is proved.
\end{abstract}

Keywords: competitiveness, competitiveness assessment indicators, competitiveness factors, higher education institution, labor market, market of educational services

\section{Introduction}

In contemporary foreign and domestic systems of scientific knowledge there were various approaches to determination of institution competitiveness (Porter, 1993, Veryaskin, 2005, Zeer, Pavlova, \& Sadovnikov, 2004; Zimnyaya, 2001), which analysis allowed to allocating the main attributes characterizing the category "higher education institution competitiveness" taking into account specifics of higher education institution activities:

1) Aiming at target markets: under current conditions the competitive relations between higher education institutions are developed in three key markets - the market of education services, the market of scientific research and development and labor market that requires reflection of this aspect in the category definition of "higher education institution competitiveness". While orienting only to the target markets (i.e. consumers) cannot be as the characteristic of higher education institution competitiveness which is both the subject of market economy and a social institution. The social orientation of higher education institution activities predetermines the need for its orientation not only to consumers, but also to all groups of interested parties (stakeholders) a higher education institution interacts with (students, business community, the state, the society, employees). Thus, the most important attribute of the category "higher education institution competitiveness" is targeting at stakeholders' needs that characterizes an ability of a higher education institution to match the needs and interests of involved parties primary groups.

2) Conditions of competitive fight: higher education institution competitiveness characterizes its ability to satisfy the needs of stakeholders in the markets of educational services, scientific research and development and labor under more attractive conditions, than other higher education institutions; 
3) Forming the attitude to performance enhancing: higher education institution competitiveness characterizes its ability to adapt to the changing environmental conditions on timely basis and to achieve desirable results (non-financial and financial ones). Unlike business the purpose of higher education institution activities is not making profit, and therefore higher education institution competitiveness characterizes its ability to reach not so many economic results but many social, scientific, scientific and technical ones.

Thus, the general competitiveness of a higher education institution is defined by its competitiveness in all three markets of presence on the basis of meeting the corresponding external stakeholders' needs to the fullest extent:

- in the educational services market: meeting the needs of high-quality educational services for students, business community, the society, the state;

- in the market of scientific research and development: meeting the needs of business community, the state for the results of research and development; meeting the needs of society for scientific values;

- in the labor market: matching the needs of business community and the state for highly qualified personnel; matching the needs of society for decline in unemployment.

That should be noted that the most important characteristic of the general competitiveness of a higher education institution is also satisfaction of internal stakeholders-employees that, in our opinion, is reached by means of implementing two directions:

- meeting the needs of workers in decent working conditions;

- meeting the needs of external stakeholders to the fullest extent allowing workers to be proud of the belonging to a higher education institution.

Thus, competitiveness of a higher education institution characterizes its ability to meet the needs of internal and external stakeholders on the basis of available competitive advantages which are formed under the influence of set of internal and external conditions (competitiveness factors). The internal factors of higher education institution competitiveness are defined by the condition of its internal environment (the condition of potential as the whole complex of personnel, intellectual, material, financial, infrastructure resources and features of carrying out internal processes - educational, research, administrative ones). The macro environment factors (social, scientific and technical, economic, political and legal) caused by the policy of the state and the microenvironment factors caused by the activity of the direct higher education institution environment (students, business community, society in general) belong to the external factors of competitiveness

The analysis of internal and external factors of higher education institution competitiveness (Baydenko, 2010; Kiryakova \& Mityaev, 2005) allows to drawing the following conclusions.

Firstly, relationship of higher education institution with internal and external stakeholders take an important place in the factor system of higher education institution competitiveness: the positive influence of a group of stakeholders on higher education institution activities forms competitive advantages and allows to matching the needs of other groups of stakeholders in the particular markets that provides higher education institution competitiveness in general. So, stable relationship of a higher education institution with business community allows to satisfying the needs of students for a practice oriented educational process that creates competitive advantages to a higher education institution both in the markets of educational services and labor. Thus, the special place in relationship structure of a higher education institution with stakeholders in the context of competitiveness is taken by the relations of a higher education institution with competitors: competitors' activities are one of external factors of higher education institution competitiveness, however, their needs and interests are not the target of high school competitiveness.

Secondly, in the conditions of a tough competitive fight between higher education institutions in the national and international markets of educational services, scientific research and development and labor, complex introduction of innovations to all spheres of its activity which allows to satisfying the existing and perspective needs of internal and external stakeholders fully and reaching steady functioning becomes the most important factor of competitiveness of a higher educational institution.

Thus, the problem of competitiveness enhancement for domestic higher education institutions is very vital that demands development of a high school competitiveness assessment technique.

The analysis of the literature (Dzhurinsky, 2007; Fakhiev, 2003; Huseynov, 2005; Richardson \& Weber, 1978) has showed that there are currently no standardized methods to assess competitiveness of higher educational institutions, which is largely due to the specific functioning of universities in the market economy. However, the assessment of university competitiveness becomes important because its results are, on the one hand, the starting 
point for the development strategy and the methods to improve competitiveness of higher education institutions, and, on the other hand, these results affect the loyalty of stakeholders, that interact with universities. In our opinion, the method of assessing university competitiveness should include the following information:

1) Assessment development of overall university competitiveness and its competitiveness in the specific target markets. This aspect is important, because the level of university competitiveness in specific target markets may vary, and overall competitiveness of the higher education institutions is determined by its ability to meet the needs of stakeholders in all markets more fully - the market of educational services, the market of research and development and labor market;

2) Records of all internal and external factors of university competitiveness. This aspect involves grouping indicators to assess university competitiveness within the framework of internal and external factors;

3) The use of the subjective and objective approach to assess indicators of university competitiveness. There is the following principle: the indicators of university competitiveness in the subjective and objective approach, which directly affects the satisfaction of interested parties, should be subjectively assessed from the perspective of stakeholders. These indicators include all indicators that characterize the quality of internal processes of the university and are determined by factors of competitiveness, such as the quality of services, pricing, advertising, corporate culture, innovation. The other indicators of university competitiveness, which are determined by the potential condition, especially the features of micro and macro factors, are evaluated objectively on the basis of official information of higher education institution activities. One of the official sources in this case can be data for higher education institutions effectiveness monitoring.

\section{Data}

2.1 From Our Point of View, a Higher Education Institution Competitiveness Assessment Technique is to Reflect Obligatorily the Following Aspects

1) Formation of the higher education institution general competitiveness and its competitiveness assessment in the separate target markets. This aspect plays an important role as the competitiveness level of a higher education institution in the separate target markets can differ, thus the general competitiveness of a higher education institution is defined by its ability to meet stakeholders' needs to the fullest extent in all markets of presence - the markets of educational services, scientific research and development and labor;

2) Taking into account all internal and external factors of higher education institution competitiveness. This aspect assumes indicator classification of a higher education institution competitiveness assessment within internal and external factors;

3) Use of the subjective and objective approach to an indicator assessment of higher education institution competitiveness. In our opinion, the following principle is the cornerstone of the subjective and objective approach: indicators, competitiveness of a higher education institution that influence satisfaction of interested parties directly, are subject to value judgment from the standpoint of stakeholders. All the indicators that characterize the quality of higher education institution internal processes belong to such indicators, and are defined by such competitiveness factors as quality of the rendered services, the price policy, advertizing, corporate culture, innovations. The other indicators of higher educational institution competitiveness defined by the condition of potential, micro and macro environment factor features of a higher education institution are estimated objectively on the basis of official sources of information on higher education institution activities. The monitoring data of higher education institution efficiency can be one of official sources in this case.

In total, in our opinion, the technique of a higher education institution competitiveness assessment is to include the following stages:

1) Formation of higher education institution competitiveness assessment indicators and their classification by types of competitiveness;

2) Distribution of higher education institution competitiveness assessment indicators according to priorities;

3) An indicator assessment on the basis of the subjective and objective approach;

4) An assessment of higher education institution competitiveness integrated indicators (the general one and by types of competitiveness)

2.2 Formation of Higher Education Institution Competitiveness Assessment Indicators and Their Classification by Types of Competitiveness

In our opinion, the following indicators can be used as higher education institution competitiveness assessment 
indicators (Table 1).

Table 1. Higher education institution competitiveness indicators

\begin{tabular}{lll}
\hline $\begin{array}{l}\text { Types } \\
\text { competitiveness }\end{array}$ & of Factors of competitiveness & Assessment indicators of competitiveness \\
\hline
\end{tabular}

1) Competitiveness $\cdot$ Teaching staff

in the market of

educational services

- The share of Scientific and Teaching Workers having a Ph.D. in the total amount of Scientific and Teaching Workers;

- The share of Scientific and Teaching Workers having a Doctor of Science degree, in the total amount of Scientific and Teaching Workers;

- The share of Scientific and Teaching Workers having a Ph.D. and a Doctor of Science degree in the total amount of Scientific and Teaching Workers (excluding part-time staff and personnel working under civil-law workers);

- The share of Scientific and Teaching Workers having a Ph.D. and a Doctor of Science degree per 100 students;

- The share of full-time employees in the total amount of Academic Teaching Staff;

- Material and technical - The total area of teaching and laboratory space, per facilities student;

- The amount of personal computers per student;

- The amount of printed educational publications (including textbooks and manuals) of the total amount of items that are registered in the library fund per student;

- Budgetary and non-budgetary sources of funding

- The ration of budgetary and non-budgetary sources of financing in the educational activity;

- Higher education and - The amount of higher education programs;

secondary vocational education - The amount of additional education programs; programs

- The quality of services

- Students' satisfaction with the quality of educational process;

- Employers' satisfaction with the competence of graduates;

- Pricing Policy

- Students' satisfaction with the university pricing policy;

- Advertising

- Applicants' satisfaction with the university advertising campaign;

- HR policy

- The ration of Scientific and Teaching Workers' average salary to the average salary in accordance with the region economy;

- Corporate culture of the - Scientific and Teaching Workers' satisfaction with university the corporate culture of the university;

- Innovation - Availability of innovative educational technologies;

- Students' satisfaction with the innovative technologies in the educational process; 
- The demand for educational services

- Demographics

- The economic situation

- The political situation

- State policy in the market of educational services

2) Competitiveness

- Teaching staff

in the market of

research and

development
- The average CSE score of students enrolled on the results of CSE on full-time tuition for undergraduate and specialist programs at the expense of the budget system of the Russian Federation;

- The average CSE score of students enrolled on the results of CSE on full-time tuition for undergraduate and specialist programs with payment of the tuition fee by individuals and legal entities;

- The amount of students, winners of the final stage of the All-Russian Olympiads, members of national teams of Russia (who have taken part in international competitions), enrolled for the full-time undergraduate and specialist programs without entrance examinations;

- The amount of applicants per place;

- The degree of the favorable conditions development for demographics;

- The degree of the favorable conditions development for the economic situation;

- The degree of the favorable conditions development for the political situation;

- The policy state in the market of educational services ;

- The share of Scientific and Teaching Workers having a $\mathrm{PhD}$ in the total amount of Scientific and Teaching Workers;

- The share of Scientific and Teaching Workers having a Doctor of Science degree in the total amount of Scientific and Teaching Workers;

- The share of Scientific and Teaching Workers having a $\mathrm{PhD}$ and a Doctor of Science degree in the total amount of Scientific and Teaching Workers (excluding part-time staff and personnel working under civil-law workers);

- The share of Scientific and Teaching Workers having a PhD and a Doctor of Science degree per 100 students;

- The share of full-time employees in the total amount of Academic Teaching Staff;

- Intellectual property

- The amount of license agreements;

- The share of funds received by the university while managing the intellectual property in the total income of the university;

- Material and technical - Area available for research units; facilities

- The share of the machinery and equipment cost (not older than 5 years) in the total value of the university machinery and equipment;

- Budgetary and non-budgetary - The ration of budgetary and non-budgetary sources sources of funding of financing in scientific and research activity;

- The development of - The amount of the university infrastructural assets; 
innovation infrastructure

- The quality of services

- Advertising

- HR policy

- Corporate culture of the university

- Innovation

- The demand for research and development

- Demographics

- The economic situation

- The political situation

- State policy in the market of educational services

3) Competitiveness in the labor market

- The quality of services

- The demand for graduates
- Consumers' satisfaction with the quality of research and development;

- Consumers' satisfaction with the university advertising campaign;

- The ration of Scientific and Teaching Workers' average salary to the average salary in accordance with the economy of the region;

- Scientific and Teaching Workers' satisfaction with the corporate culture of the university;

- The total amount of innovative products of the university;

- The amount of contracts / agreements to be made by R \& D;

- The total R \& D;

- The degree of the favorable conditions development for demographics;

- The degree of the favorable conditions development for the economic situation;

- The degree of the favorable conditions development for the political situation;

- The amount of state support programs of research activities where the university can participate;

- Employers' satisfaction with the competence of graduates;

- The percentage of graduates who applied for assistance in finding employment;

- The percentage of graduates employed in their field.

\section{Results}

\subsection{Distribution of Higher Education Institution Competitiveness Assessment Indicators according to Priorities}

Distribution according to priorities is made for the purpose of ratio determination of assessment separate indicators in the total value of an integrated indicator of a higher education institution competitiveness assessment. In our opinion, the criterion of competitiveness factor influence extent (within which indicators are grouped) for achievement of higher education institution competitiveness in the markets of educational services, scientific research and development and labor is to be the basis for distribution of assessment indicators according to priorities. In accordance with this criterion three primary groups of higher education institution competitiveness assessment indicators according to priorities can be allocated:

- Priority No. 1 (P1): the assessment indicators grouped within the factors of competitiveness characterizing internal processes of a higher education institution and special features of its microenvironment development;

- Priority No. 2 (P2): the indicators, estimates grouped within the factors of competitiveness characterizing the condition of higher education institution internal capacity;

- Priority No. 3 (P3): the assessment indicators grouped within the factors of competitiveness characterizing development features of the higher educational institution macro environment.

Thus we believe that indicators of the 1 st and 2 nd priorities are 5 and 3 times more significant than indicators of the 3rd priority respectively. Thus, the indicator ratio of the 1 st priority group will make the $0.556,2$ priority $-0.333,3$ priority -0.111 . In this way, all the indicators as a part of the relevant group of a priority will have the identical ratio determined by the attitude of the priority group ratio towards the quantity of the relevant group indicators. 


\subsection{An Indicator Assessment on the Basis of the Subjective and Objective Approach}

In accordance with the subjective and objective approach to all indicators assessment can be divided into two categories:

1) The quality indicators of a competitiveness assessment characterizing the degree of stakeholders' satisfaction that higher education institutions interact with are defined subjectively, on the basis of a score expert assessment of stakeholders (subjective approach).

In our opinion, the experts have to act for a competitiveness quality indicators assessment:

- Students, employers, the personnel of higher education institution (for the definition of competitiveness quality indicators in the market of educational services);

- Enterprises of real production sector, higher education institution personnel (for definition of quality indicators of a higher education institution competitiveness in the market of scientific research and development);

- Employers (for the definition of quality indicators of higher education institution competitiveness in the labor market).

Within the technique offered by the authors the five-grade assessment system (Table 2) is used.

Table 2. Scoring assessment system of the quality indicators of university competitiveness

\begin{tabular}{lll}
\hline Satisfaction level & Characteristics of indicators & Grades \\
\hline Minimum & $\begin{array}{l}\text { Extremely low satisfaction level or dissatisfaction with the } \\
\text { university activities } \\
\text { Low }\end{array}$ & $\begin{array}{l}\text { Low satisfaction level with the university activities: there are a lot } \\
\text { of deficiencies in the university activities }\end{array}$ \\
Average & $\begin{array}{l}\text { Average satisfaction level with the university activities: the } \\
\text { university activities are carried out at an acceptable level with } \\
\text { some shortcomings }\end{array}$ \\
High & $\begin{array}{l}\text { High satisfaction level: the university activities almost completely } \\
\text { meet the requirements } \\
\text { Maximum }\end{array}$ & $\begin{array}{l}\text { Maximum satisfaction level: the university activities completely } \\
\text { meet the requirements }\end{array}$ \\
\hline
\end{tabular}

2) the quantitative indicators of a competitiveness assessment reflecting objectively a higher education institution capacity condition, implementation of its internal processes and the macro environment influence are defined directly on the basis of measurements according to the official sources (an objective approach). The main official source forming the basis for formation of quantitative competitiveness indicators, is the higher education institution efficiency monitoring data which is annually carried out by the Ministry for Education and Science of the Russian Federation. Other quantitative indicators are formed on the basis of reports on higher educational institution activities.

It should be noted that there are also type indicators "yes/no" measured by logical values ( 0 - No, 1 - yes) (the indicators determined by macro environment factor features of a higher education institution and characterizing degree of macro environment usefulness) in the composition of competitiveness assessment indicators. In our opinion, the assessment of such indicators has to be made objectively, on the basis of official data on the established economic, political situation, etc.

For ensuring commensurability of estimated indicators quantitative indicators of a higher education institution competitiveness assessment are subject to rationing (in accordance with quality indicators according to a 5-mark scale). The rated value of a quantitative indicator can be calculated by formula:

$$
\mathrm{P}=5 * \mathrm{P}_{\mathrm{abc}} / \mathrm{P}_{\max (\min )}
$$

where $\mathrm{P}_{\mathrm{abc}}$ is the actual value of a higher education institution competitiveness assessment indicator; $\mathrm{P}_{\max (\min )}$ is the normalized value of a higher education institution competitiveness assessment indicator. 
As the normalized value of a quantitative index its calibrated value (the maximum or minimum size) $\left(\mathrm{P}_{\max (\min )}\right)$ is accepted which characterizes activities of leading higher education institutions for this indicator in the regional markets of educational services, scientific research and development, labor.

Therefore all quality and quantitative indicators of a higher education institution competitiveness assessment are gaining mark value and getting comparable.

\section{Discussions}

Ensuring competitiveness of a contemporary university is one of the most important factors of providing its sustainable development in the long term. In this regard development of methodical tools of a university competitiveness level assessment is gaining special relevance. The research was conducted on the basis of several leading universities of the Russian Federation.

The conducted research allowed revealing the need for implementation of the following changes in contemporary university development directed at their competitiveness enhancement. The changes are connected with the main stakeholders of a university. These are a person, a family, professional communities, business and the state. The students and their parents are interested in university system changes the least since it is difficult to estimate their role in implementation of changes for them. Professional communities are interested in higher education system changes at more considerable degree since the rights by means of certification, examinations or tests are reserved for them in order to carry out an assessment of professional level university graduates, i.e. its competitiveness enhancement. Also competitiveness university growth is very important for business, since high professional level of enterprise employees is the most important element of ensuring efficiency of business development in general.

The most powerful customer of changes in higher education system in the Russian Federation is the state which has been carrying out active university reforming for several years and on the basis of an independent university competitiveness assessment by means of the developed indicator system of higher education institution efficiency monitoring.

\section{Conclusions}

The integrated indicators of a higher education institution competitiveness assessment offered by the authors allow judging its ability to meet stakeholders' needs both in the separate target markets and in general.

On the whole, the offered technique can form the basis for a higher education institution competitiveness assessment that will allow increasing public policy efficiency in the field of enhancing higher education institution competitiveness and predicting university development more precisely in the long term.

\section{Acknowledgments}

The authors thank all participants of this study for their kind cooperation.

\section{References}

Baydenko, V. I. (2010). The main trends in the development of higher education: Global and Bologna measurement (p. 352). Moscow Research Center of the quality of training MISA.

Dzhurinsky, A. N. (2007). Integration of educational space in Western Europe. In Human resources for innovation development of the educational system: Mat-ly I Vseros (pp. 25-29). Moscow: IASP.

Fakhiev, H. A. (2003). How to measure the competitiveness of enterprise? Marketing in Russia and abroad, 4, 112-123.

Huseynov, L. A. (2005). Globalization and socio-cultural development of regional systems of education. Higher education today, 4, 52-55.

Kiryakova, A. V. (2005). Russia's integration into the international educational space (p. 40). Orenburg: IPK GOU OSU.

Mityaev, A. M. (2005). Features of the system of training in the modern university. Pedagogy, 8(1), 71-73.

Porter, M. (1993). Competition (p. 143). Moskow: International relations.

Richardson, J. (1996). Learning the way to the cooperative school. School team innovator, 1, 2-6.

Veryaskin, V. P. (2005). Values and normative sources of the concept of human development. Man, 2, 41-45.

Weber, M. (1978). Economy and Society (Vol. 2., p. 377). University of California Press.

Zeer, E. F., Pavlova, A. M., \& Sadovnikov, O. N. (2004). Proforientologiya: Theory and Practice (p. 304). 
Ekaterinburg: Business book.

Zimnyaya, I. A. (2001). Key competences new paradigm of education result. Higher education today, $5,3442$.

\section{Copyrights}

Copyright for this article is retained by the author(s), with first publication rights granted to the journal.

This is an open-access article distributed under the terms and conditions of the Creative Commons Attribution license (http://creativecommons.org/licenses/by/3.0/). 